\title{
Differences in mortality and suicidal behaviour between treated and never-treated people with schizophrenia in rural China
}

\author{
Mao-Sheng Ran, Cecilia Lai-Wan Chan, Eric Yu-Hai Chen, Wen-Jun Mao, Shi-Hui Hu, \\ Cui-Ping Tang, Fu-Rong Lin and Yeates Conwell
}

\section{Background}

Many people with schizophrenia remain untreated in the community. Long-term mortality and suicidal behaviour among never-treated individuals with schizophrenia in the community are unknown.

\section{Aims}

To explore 10-year mortality and suicidal behaviour among never-treated individuals with schizophrenia.

\section{Method}

We used data from a 10-year prospective follow-up study (1994-2004) among people with schizophrenia in Xinjin County, Chengdu, China.

\section{Results}

The mortality rate for never-treated individuals with schizophrenia was 2761 per 100000 person-years during follow-up. There were no significant differences of rates of suicide and all-cause mortality between never-treated and treated individuals. The standardised mortality ratio (SMR) for never-treated people was 10.4 (95\% Cl 7.2-15.2) and for treated individuals $6.5(95 \% \mathrm{Cl} 5.2-8.5)$. Compared with treated people, never-treated individuals were more likely to be older, poorer, have a longer duration of illness, marked symptoms and fewer family members

\section{Conclusions}

The never-treated individuals have similar mortality to and a higher proportion of marked symptoms than treated people, which may reflect the poor outcome of the individuals without treatment. The higher rates of mortality, homelessness and never being treated among people with schizophrenia in low- and middle-income nations might challenge presumed wisdom about schizophrenia outcomes in these countries.

\section{Declaration of interest}

None.
It is an axiom in international psychiatry that schizophrenia has a better course and outcome in low- and middle-income countries. ${ }^{1,2}$ Although a few important cross-national studies by the World Health Organization (WHO) support the 'better prognosis' hypothesis, ${ }^{3-6}$ it may be premature to conclude that further examination of the question is not necessary. ${ }^{7,8}$

A considerable number of individuals with schizophrenia go undiagnosed and untreated in low- and middle-income countries. ${ }^{9-11}$ Mortality is higher in people with schizophrenia than in the general population, ${ }^{5,12,13}$ and the differential mortality gap between people with schizophrenia and the general population has worsened in recent decades. ${ }^{13}$ Suicide is one of the most common causes of premature death in individuals with schizophrenia. ${ }^{14-17}$ However, no studies on mortality and rates of suicide in never-treated people with schizophrenia have been reported. $^{7}$

Compared with urban areas, mental health services are less available and more people may never accept treatment in rural China. ${ }^{18}$ Lack of knowledge of medical treatment may influence the beliefs of individuals and their families about medication. ${ }^{18}$ Knowledge of different outcomes between never-treated and treated people with schizophrenia may change the attitudes of people and their families towards medication and improve the rate of drug treatment.

Knowledge of psychopathology in untreated individuals would be helpful to identify the natural state of the illness and improve understanding of the pathology underlying the illness. ${ }^{19}$ Knowledge about never-treated individuals should also be meaningful for clinical services and understanding of the neuropathology of the illness.

The objectives of this long-term prospective follow-up study in people with schizophrenia in rural China were: to compare the rates of all-cause mortality and suicide between never-treated and treated individuals with schizophrenia; and to explore the characteristics of never-treated people.

\section{Method}

\section{Study population}

All participants with schizophrenia $(n=510)$ were identified from an epidemiological investigation of 123572 people aged 15 years and older in six townships of Xinjin County in March 1994. Participants were identified through screening procedures for psychosis and general psychiatric interview. The details of this investigation have been described in previous papers. ${ }^{10,20}$ All participants lived in rural communities and met ICD-10 criteria $^{21}$ for a diagnosis of schizophrenia based on standardised administration of the Present State Examination (PSE-9) ${ }^{22}$ by trained research interviewers. Using the baseline data in 1994 we followed up and interviewed all the participants with schizophrenia and their informants in May 2004. All respondents gave informed consent.

\section{Measurements}

The principal assessment tools included the PSE-9 and Social Disability Screening Schedule (SDSS) ${ }^{23}$ in the baseline investigation in $1994 .^{10,20}$ For individuals still alive at the visit in 2004, at least one person familiar with each participant's life and circumstances and/or the participant themselves were interviewed. ${ }^{7}$ For participants now deceased, the next-of-kin or at least one person familiar with the person was interviewed. All interviews were conducted by trained psychiatrists using the Patients Follow-up Schedule $(\mathrm{PFS})^{7}$ for about $30 \mathrm{~min}$. For all 
participants, medical and psychiatric treatment records were obtained from hospitals, village doctors' clinics and traditional healers. For participants now deceased, information from the death certification and suicide note, where applicable, was also obtained.

Participants were defined as 'never-treated' if the individual and/or informants reported that they had not received any antipsychotic medication since their first episode of schizophrenia. The never-treated participants were classified according to the treatment information collected in 1994 and 2004, which included participant and/or informant reports, treatment records in hospitals, village doctor's clinics and traditional healers.

The classification of each death as a result of suicide or other causes represented the consensus opinion of interviewers and independent researchers after reviewing all information obtained during the interviews. Information from the death certification and suicide note (where applicable) was also obtained. Participants were defined as homeless and lost to follow-up if informants reported that they had wandered and slept in public places and that their whereabouts was unknown. ${ }^{7}$ Participants' physical illnesses (e.g. diseases of heart and lung, hypertension and cancer) at some time during the follow-up period were defined according to the informants' report and doctors' diagnoses. Marked symptoms (significant positive and/or negative symptoms, mood symptoms or resulting behavioural disturbance) were defined according to the PSE-9.22

\section{Statistical analysis}

The follow-up period for every participant started at recruitment and ended either at interview, death or the point at which they were lost to follow-up. Mortality rates were calculated overall and by subgroups defined according to various characteristics. Mortality rates were estimated using the person-time method (number of deaths divided by person-years of follow-up). The effects of antipsychotic treatment on mortality and suicide rates were tested using univariate Cox hazard regression analyses. Survival analyses were also used to explore treatment differences in survival rates.

Standardised mortality ratios (SMRs) were calculated by dividing observed deaths by expected deaths, with the general population in Xinjin County used as a standard population. Death registration data of Xinjin County were used for the general population. All the variables analysed were based on the measures at baseline or follow-up.

\section{Results}

\section{Characteristics of the cohort participants}

Of 510 individuals identified as having schizophrenia in 1994, 10 people did not complete the evaluation. The remaining 500 participants $(98.0 \%, 500 / 510)$ were available for follow-up (19942004 ), of which $46.6 \%$ were male, $64.2 \%$ were married, and in $55.8 \%$ the family's economic status was less than the mean.
All 500 participants included in 1994 were followed up from 1994 to 2004. Informants were available for all these participants (100\%). Information on 305 participants was provided by both the individual and their informants, and information on 195 participants was provided by proxy informants alone.

\section{Differences between never-treated and treated participants}

At the end of the follow-up period, 132 participants (or their proxy informants) (26.4\%) reported never having received antipsychotic treatment and $368(73.6 \%)$ reported having received antipsychotic treatment for their schizophrenia (Table 1). Among the treated individuals, there were 117 people $(31.8 \%)$ who had been admitted to a mental hospital, and 133 individuals (36.1\%) who had accepted antipsychotic treatment for less than 2 months. Compared with treated participants (traditional Chinese medicine $45.7 \%$, treatment by traditional healers $61.7 \%)$, never-treated people had received significantly less traditional Chinese medicine (13.6\%) and treatment by traditional healers $(34.1 \%)$.

The characteristics of never-treated and treated participants are described in Table 2. Compared with treated participants, never-treated participants were significantly older, less likely to be married, had a lower education level and fewer family members. Caregivers of never-treated people were less likely to be a parent or spouse. The never-treated individuals were significantly older at age at onset, more likely to live alone, had longer duration of illness, more marked symptoms and fewer previous suicide attempts.

\section{Current status and mortality}

In 2004, as indicated in Table 3, there were no significant differences between never-treated $(70.5 \%)$ and treated participants $(75.8 \%)$ in the percentage that had survived. There were also no significant differences between never-treated (5.3\%) and treated participants $(6.3 \%)$ in the proportion that were homeless. The percentage of never-treated individuals who died by suicide $(3.0 \%)$ was similar to that in those who had been treated $(4.6 \%)$. Deaths from other causes were significantly more frequent in never-treated $(21.2 \%)$ than treated $(13.3 \%)$ people during the follow-up period.

There were no significant differences between male nevertreated and treated participants in the percentage surviving at follow-up, who had died by suicide or other causes, or who were homeless. However, deaths from other causes were significantly more frequent in female never-treated $(20.0 \%)$ than treated (10.4\%) participants during the follow-up period. Among never-treated individuals, there were no significant differences between men $(44.8 \%)$ and women $(44.6 \%)$ in the percentage who were unable to work. Among treated participants, there were significantly more men $(41.6 \%)$ with an inability to work than women $(32.2 \%)\left(\chi^{2}=10.1\right.$, d.f. $\left.=2, P<0.01\right)$.

The mortality rates and SMR of never-treated and treated participants are shown in Table 4. There was no significant

\begin{tabular}{|c|c|c|c|c|}
\hline & $\begin{array}{l}\text { Treated participants, } n \text { (\%) } \\
\qquad n=368\end{array}$ & $\begin{array}{l}\text { Never-treated participants, } n(\%) \\
\qquad n=132\end{array}$ & $\chi^{2}$ & $\begin{array}{l}\text { Odds ratio } \\
(95 \% \mathrm{Cl})\end{array}$ \\
\hline Antipsychotic drugs & $368(100)$ & $0(0)$ & & \\
\hline Traditional Chinese medicine & $168(45.7)$ & $18(13.6)$ & $42.63^{* * *}$ & $3.75(2.36-5.96)$ \\
\hline Treatment by traditional healers & $227(61.7)$ & $45(34.1)$ & $29.82^{\star * *}$ & $1.35(1.20-1.51)$ \\
\hline
\end{tabular}




\begin{tabular}{|c|c|c|c|c|c|}
\hline \multirow[b]{2}{*}{ Variable } & \multirow[b]{2}{*}{ Never-treated participants $(n=132)$} & \multirow[b]{2}{*}{ Treated participants $(n=368)$} & \multicolumn{3}{|c|}{ Analysis } \\
\hline & & & Test & d.f. & $P$ \\
\hline Gender, male: $n(\%)$ & $67(50.8)$ & $166(45.1)$ & $\chi^{2}=1.3$ & 1 & 0.26 \\
\hline \multicolumn{6}{|l|}{ Marital status, $n(\%)$} \\
\hline Married & $73(55.3)$ & $248(67.4)$ & $x^{2}=6.2$ & 1 & 0.01 \\
\hline Single & $29(22.0)$ & 75 (20.4) & $\chi^{2}=0.2$ & 1 & 0.70 \\
\hline Divorced & $11(8.3)$ & $23(6.2)$ & $\chi^{2}=0.7$ & 1 & 0.42 \\
\hline Bereavement & $19(14.4)$ & $22(6.0)$ & $\chi^{2}=9.1$ & 1 & $<0.01$ \\
\hline Education (primary school), $n$ (\%) & $113(85.6)$ & $253(68.8)$ & $\chi^{2}=14.1$ & 1 & $<0.01$ \\
\hline Family economic status (< mean), $n(\%)$ & $81(61.4)$ & $197(53.5)$ & $\chi^{2}=2.4$ & 1 & 0.12 \\
\hline Family history of mental illness, $n$ (\%) & $34(25.8)$ & $107(29.1)$ & $\chi^{2}=0.5$ & 1 & 0.47 \\
\hline \multicolumn{6}{|l|}{ Caregivers, $n$ (\%) } \\
\hline Parent & $15(11.4)$ & $78(21.2)$ & $\chi^{2}=6.2$ & 1 & 0.01 \\
\hline Spouse & $50(37.9)$ & $196(53.3)$ & $\chi^{2}=9.2$ & 1 & $<0.01$ \\
\hline Children & $19(14.4)$ & $36(9.8)$ & $\chi^{2}=2.1$ & 1 & 0.15 \\
\hline Others & $11(8.3)$ & $20(5.4)$ & $\chi^{2}=1.4$ & 1 & 0.24 \\
\hline None & $37(28.0)$ & $38(10.3)$ & $\chi^{2}=23.9$ & 1 & $<0.01$ \\
\hline Live alone, $n(\%)$ & $29(22.0)$ & $24(6.5)$ & $\chi^{2}=24.5$ & 1 & $<0.01$ \\
\hline Inability to work, $n(\%)$ & $30(22.7)$ & $67(18.2)$ & $\chi^{2}=1.3$ & 1 & 0.26 \\
\hline With marked symptoms, $n$ (\%) & $101(76.5)$ & $206(56.0)$ & $\chi^{2}=17.3$ & 1 & $<0.01$ \\
\hline Living in stable house, ${ }^{a} n(\%)$ & $106(80.3)$ & $334(90.8)$ & $\chi^{2}=10.1$ & 1 & $<0.01$ \\
\hline Previous suicide attempts, ${ }^{a} n$ (\%) & $7(5.3)$ & $69(18.8)$ & $\chi^{2}=13.6$ & 1 & $<0.01$ \\
\hline Physical illness, ${ }^{a} n(\%)$ & $34(25.8)$ & $100(27.2)$ & $\chi^{2}=0.1$ & 1 & 0.75 \\
\hline Age, years: mean (s.d.) & $50(16.0)$ & $42.9(15.0)$ & $t=4.6$ & 498 & $<0.01$ \\
\hline Duration of illness: mean (s.d.) & $15.4(13.1)$ & $11.5(10.4)$ & $t=3.4$ & 496 & $<0.01$ \\
\hline Age at onset: mean (s.d.) & $34.2(14.1)$ & $30.1(12.5)$ & $t=3.1$ & 496 & $<0.01$ \\
\hline Number of family members: mean (s.d.) & $3(1.7)$ & $3.6(1.4)$ & $t=3.8$ & 495 & $<0.01$ \\
\hline
\end{tabular}

\begin{tabular}{|c|c|c|c|c|c|c|}
\hline \multirow[b]{2}{*}{ Current status } & \multicolumn{3}{|c|}{ Never-treated participants, $n(\%)$} & \multicolumn{3}{|c|}{ Treated participants, $n$ (\%) } \\
\hline & Male & Female & Total & Male & Female & Total \\
\hline Survivals & $44(65.6)$ & $49(75.4)$ & $93(70.5)$ & $115(69.3)$ & $164(81.2)$ & $279(75.8)$ \\
\hline \multicolumn{7}{|l|}{ Deaths } \\
\hline $\begin{array}{l}\text { Suicide } \\
\text { Deaths from other causes }\end{array}$ & $\begin{array}{c}4(6.0) \\
15(22.4)\end{array}$ & $\begin{array}{c}0(0.0) \\
13(20.0)^{\mathrm{a}}\end{array}$ & $\begin{array}{c}4(3.0) \\
28(21.2)^{b}\end{array}$ & $\begin{array}{c}11(6.6) \\
28(16.9)\end{array}$ & $\begin{array}{c}6(3.0) \\
21(10.4)^{\mathrm{a}}\end{array}$ & $\begin{array}{r}17(4.6) \\
49(13.3)^{b}\end{array}$ \\
\hline Homeless and lost to follow-up & $4(6.0)$ & $3(4.6)$ & $7(5.3)$ & $12(7.2)$ & $11(5.4)$ & $23(6.3)$ \\
\hline Total & $67(50.8)$ & $65(49.2)$ & $132(26.4)$ & $166(45.1)$ & $202(54.9)$ & $368(73.6)$ \\
\hline
\end{tabular}

\begin{tabular}{|c|c|c|c|c|c|}
\hline & \multicolumn{2}{|c|}{ Never-treated participants } & \multicolumn{2}{|c|}{ Treated participants } & \multirow[b]{2}{*}{ Hazard ratio $(95 \% \mathrm{Cl}$} \\
\hline & Rate & SMR (95\% Cl) & Rate & SMR $(95 \% \mathrm{Cl})$ & \\
\hline Suicide & 345.1 & $32.5(26.8-47.0)$ & 520.4 & $46.7(27.8-51.3)$ & $1.2(0.4-3.7)$ \\
\hline Deaths from other causes & 2415.9 & $9.5(6.2-14.0)$ & 1199.9 & $5.9(4.9-7.0)$ & $1.0(0.6-1.6)$ \\
\hline Total deaths & 2761.0 & $10.4(7.2-15.2)$ & 1720.3 & $6.5(5.2-8.5)$ & $1.1(0.7-1.7)$ \\
\hline
\end{tabular}

difference between the mortality rate in never-treated and treated individuals using Cox hazard regression analyses.

There were no significant differences in suicide rates between never-treated (345.1 per 100000 person-years) and treated participants (520.4 per 100000 person-years) using Cox hazard regression analyses. The SMR for never-treated individuals who died by suicide was 32.5 , and for treated individuals 46.7 .

There were no significant differences in the mortality rate from other causes (accidental and natural) between never-treated
(2415.9 per 100000 person-years) and treated participants (1199.9 per 100000 person-years) using Cox hazard regression analyses. The SMR for never-treated individuals who died from other causes was 9.5, and for treated individuals 5.9.

The survival probability for never-treated people in 2004 was 0.71 (95\% CI 0.61-0.80). There was no significant difference in survival rate between never-treated and treated participants (survival probability in 2004: $0.76,95 \%$ CI $0.71-0.81$ ) during the 10 years of follow-up (Log-rank test: $\chi^{2}=2.13, P>0.05$ ). 


\section{Discussion}

To our knowledge, this is the first long-term prospective cohort study of mortality and suicidal behaviour in people with schizophrenia in the community who had never been treated with antipsychotic medication. It includes longitudinal follow-up and analyses based on time-dependent factors. The strengths of our study include the use of a large representative community sample in rural China, its longitudinal 10-year follow-up design and high rates of participant retention.

\section{Mortality and suicide}

The results of Cox hazard regression analyses did not support differences in mortality between never-treated and treated participants with schizophrenia. The results of survival analyses also indicated that there was no significant difference in 10-year survival rates between never-treated and treated individuals. The overall mortality rates in those never-treated and those treated are extremely high, exceeding by 6.5 times the rate observed among people over 15 years old in the general population.

The results indicate that suicidal behaviour is common in never-treated and treated people with schizophrenia. The results of Cox hazard regression analyses also did not support differences in rates of suicide between never-treated and treated individuals. The suicide rate that we observed in never-treated participants is similar to the rate in those who have received treatment. Standardised mortality ratios for suicide were 32.5 in nevertreated participants and 46.7 for treated participants.

Why are there no significant differences in total mortality rates between never-treated and treated participants? Given the higher proportion of marked symptoms and longer duration of illness, it could not be because never-treated individuals had less severe illness. Thus, despite the lack of treatment, the mortality in never-treated participants still remained the same as those who received treatment. The reasons may be as follows. First, the mortality of those with schizophrenia may be influenced by multiple factors including antipsychotic medication, family care and physical status. Second, the results indicate that antipsychotic treatment may not reduce the long-term mortality rates and increase survival rates in people with schizophrenia. One study in The Netherlands indicated that there was no significant difference in the suicide rate between placebo and active treatment groups. ${ }^{24}$ Third, the effectiveness of antipsychotic treatment may be underestimated because a lot of people in the treated group had not received regular antipsychotic treatment. For example, only $31.8 \%$ of participants had been admitted to a mental hospital and $36.1 \%$ had accepted antipsychotic treatment for less than 2 months. Fourth, many people in the never-treated group received traditional Chinese medicine $(13.6 \%)$ and treatment by traditional healers $(34.1 \%)$, interventions that could potentially influence the outcome of schizophrenia. ${ }^{25}$ Further studies of never-treated individuals may be helpful to explore the differences.

Although evidence indicates that a significant proportion of treated incident cases of schizophrenia achieve favourable longterm outcomes, ${ }^{5}$ certain classes of antipsychotics have been associated with death. ${ }^{26}$ Suicide risk among people with schizophrenia-spectrum disorders declines quickly after treatment and recovery. ${ }^{27}$ However, the results of this study indicate that there are no significant differences in mortality and rates of suicide between people who had received antipsychotic treatment and those who did not. The results did not support the expectation that antipsychotic drugs could reduce the long-term mortality rates in these individuals. The long-term mortality of never-treated participants is similar to, if not higher than, the mortality of treated participants with schizophrenia.

In general, older patients are much more likely to die. ${ }^{28}$ Evidence indicated that the mortality rate was significantly higher among individuals with later onset of schizophrenia ( $>45$ years) than those with age at onset before 45 years of age. ${ }^{7}$ However, although people with a later onset may have a more benign course of illness, symptom severity and cognitive deficits may be similar in participants with early-onset and late-onset schizophrenia. ${ }^{29}$ The results of this study indicated that there were no significant differences in mortality rates between never-treated and treated participants even though never-treated people were older and had a later onset of illness than treated individuals.

The results of our study indicate that never-treated people are more likely to be older, unmarried, be of an older age at onset, longer duration of illness, fewer family members, more marked symptoms and accept less support than treated individuals in rural China. All these possible risk factors of never-treated participants identified in this study reflect the influence of both socioeconomic characteristics of rural China and the clinical characteristics of these participants. It is striking that there are no differences in mortality rates even though the untreated group is associated with a range of significant risk factors: more likely to be older, less likely to be married, have less social support and more marked symptoms. The influence of socioeconomic characteristics of participants with schizophrenia on mortality and suicide risk needs further study.

Given the similar mortality rates between never-treated and treated participants, we suggest that antipsychotic treatment may actually be ineffective in reducing mortality. However, the results of this study indicate that antipsychotic treatment might reduce long-term symptom severity. The results signified the importance of medication on reducing the psychotic symptoms. Differences in symptom severity might have an impact on other dimensions of outcome such as social function. The impact of medication on social function needs further study.

Our results indicate that there were no significant differences between male never-treated and treated participants in the percentage of survivals, suicide, deaths from other causes and homelessness. However, female never-treated participants had a higher percentage of deaths from other causes than treated participants. Male treated participants had a worse ability to work than female treated participants. Differences between genders regarding medication needs further study.

\section{Other characteristics}

Evidence indicates that the longer the psychotic symptoms continue unchecked by medication, the greater the likelihood of profound clinical deterioration. ${ }^{30}$ The results of the present study indicate that never-treated participants have significantly more marked symptoms, consistent with a previous study in Bali in which never-treated participants showed significantly higher total Positive and Negative Syndrome Scale (PANSS) scores than did those in the treated group. ${ }^{11}$ Our results may support the possibility that the severity of symptoms remains the same in untreated individuals irrespective of the duration of illness. ${ }^{19}$

The results of this study indicate that never-treated participants may be associated with lower family economic level and fewer caregivers in rural China. ${ }^{7,31}$ The small number of family members, reflecting the nuclear family, may be a risk factor related to non-treatment of individuals with schizophrenia that is different from a study in India in which the larger extended/joint family seemed to be a crucial factor associated with non-treatment. ${ }^{9}$ Caregivers were less likely to be a parent or spouse in never-treated 
participants which might also be a risk factor related to nontreatment of these individuals. Never-treated people were more likely to be older in age and ill for a longer duration than those who had been treated, which is consistent with the Indian study. ${ }^{9}$ We suggest that the traditionally supportive family network may be broken down by prolonged illness and poor clinical status. ${ }^{20,32}$ The role of families needs further study.

Evidence indicates that people with schizophrenia have high rates of potentially reversible medical morbidity that increase mortality as well. ${ }^{33,34}$ The results of this study indicate that there were no significant differences in physical illness between nevertreated and treated individuals.

\section{Implications for services}

Our results have implications for reducing mortality and suicide among never-treated and treated people with schizophrenia in China and elsewhere. The characteristics of these individuals should be taken into account when developing interventions to prevent mortality. Resources and services for mental disorders are insufficient considering the burden caused by these disorders around the world. ${ }^{35}$ Long-term outcomes of schizophrenia may be worsened as the absence of mental health services delays treatment. ${ }^{36}$ We suggest that treatment including antipsychotic medication and other interventions (such as traditional Chinese medicine) may improve outcomes for untreated individuals even though they have been ill for many years. ${ }^{37}$ Given the limited resources in contemporary China, prevention programmes should emphasise community-based mental healthcare to provide earlier diagnosis, antipsychotic treatment, treatment of comorbid medical conditions, function rehabilitation and family support. Given severe stigma associated with psychiatric illness, ${ }^{18}$ efforts to reduce stigma in the community will be necessary for individuals with schizophrenia to be accepted by the community again and interventions made to decrease their mortality rate.

The results of our long-term studies among people with schizophrenia challenge the axiom in international psychiatry that schizophrenia has a better course and outcome in low- and middle-income countries. ${ }^{1,2}$ Given the high rates of mortality, including suicide, homelessness and never-treated people with schizophrenia in low- and middle-income countries, it is premature to come to this conclusion if withdrawals or attrition due to death and homelessness and the outcome of many nevertreated participants are not included in follow-up analyses. ${ }^{7,8,38}$ It is time to re-examine presumed wisdom about schizophrenia prognosis in low- and middle-income countries. ${ }^{7,8}$

Given the representative sample used in our study, we are confident that our findings are generalisable to the population of people with schizophrenia in rural areas, and even other low- and middle-income countries that have a similar social environment. Overall, mortality, suicide and homelessness are serious concerns in never-treated and treated individuals with schizophrenia in rural China. It is crucial to supply the necessary community mental health services and medication for these people in rural China.

\section{Limitations}

Possible misclassification of never-treated and treated participants, and of suicide, may exist due to recall bias. Discrimination concerning suicidal behaviour and lack of coroners' reports may have also had an impact on the study findings. The mortality and suicide rates may be underestimated because most homeless individuals were lost to follow-up. Given the diversity of sociocultural, economic and care provision characteristics, the results of this rural China study may not generalise to high-income countries.

Mao-Sheng Ran, MD, PhD, Division of Social Work, University of Guam, Mangilao, Guam, USA: Cecilia Lai-Wan Chan, PhD, Department of Social Work and Social Guam, USA; Cecilia Lai-Wan Chan, PhD, Department of Social Work and Socia
Administration, The University of Hong Kong, Pokfulam, Hong Kong; Eric Yu-Hai Chen, MD, Department of Psychiatry, The University of Hong Kong, Pokfulam, Hong Kong; Wen-Jun Mao, MD, Shi-Hui Hu, MD, Chengdu Mental Health Center, Chengdu, China; Cui-Ping Tang, RN, Fu-Rong Lin, MD, Xinjin Mental Hospital, Xinjin, Chengdu, China; Yeates Conwell, MD, Department of Psychiatry, University of Rochester Medical Center, Rochester, New York, USA

Correspondence: Mao-Sheng Ran, Division of Social Work, University of Guam, Mangilao, Guam 96923, USA. Email: ranmaosh@yahoo.com

First received 29 Jun 2008, final revision 17 Nov 2008, accepted 30 Jan 2009

\section{Funding}

The 1994 Chengdu study was supported by a grant from the China Medical Board in New York (CMB, 92-557: MZ Xiang, PI). This work was supported in part by HKJC Centre for Suicide Research and Prevention, HKU, and ICOHRTA grant D43 TW05814 (E.D. Caine, PI) and GRIP 1 R01 TW007260-01 (M.S. Ran, PI) from the Fogarty International Center of NIH.

\section{Acknowledgements}

The authors thank Chengdu Mental Health Center and Xinjin Mental Hospital for their collaboration.

\section{References}

1 Mueser KT, McGurk SR. Schizophrenia. Lancet 2004; 363: 2063-72.

2 Isaac M, Chand P, Murthy P. Schizophrenia outcome measures in the wider international community. Br J Psychiatry 2007; 191 (suppl 50): s71-7.

3 World Health Organization. Schizophrenia: An International Follow-up Study. John Wiley and Sons, 1979.

4 Jablensky A, Sartorius N, Ernberg G, Anker M, Korten A, Cooper JE, et al. Schizophrenia: manifestation, incidence and course in different cultures. A World Health Organization ten-country study. Psychol Med Monogr Suppl 1992; 20: 1-97.

5 Harrison G., Hopper K, Craig T, Laska E, Siegel C, Wanderling J, et al. Recovery from psychotic illness: a 15- and 25-year international follow-up study. Br J Psychiatry 2001; 178: 506-17.

6 Hopper, K, Harrison G, Janca A, Sartorius N. Recovery from Schizophrenia: An International Perspective. Oxford University Press, 2007.

7 Ran MS, Chen EYH, Conwell Y, Chan CLW, Yip PSF, Xiang MZ, et al. Mortality in people with schizophrenia in rural China. 10-year cohort study $\mathrm{Br} \mathrm{J}$ Psychiatry 2007; 190: 237-42.

8 Cohen A, Patel V, Thara R, Gureje O. Questioning an axiom: Better prognosis for schizophrenia in the developing world? Schizophr Bull 2008; 34: 229-44.

9 Padmavathi R, Rajkumar S, Srinivasan TN. Schizophrenic patients who were never treated - a study in an Indian urban community. Psychol Med 1998; 28: $1113-7$.

10 Ran MS, Xiang MZ, Huang MS, Shan YH. Natural course of schizophrenia: 2-year follow-up study in a rural Chinese community. Br J Psychiatry 2001; 178: $154-8$

11 Kurihara T, Kato M, Reverger R, Tirta IGR, Kashima H. Never-treated patients with schizophrenia in the developing country of Bali. Schizophr Res 2005; 79: 307-13.

12 Harris EC, Barraclough B. Suicide as an outcome for mental disorders. A meta-analysis. Br J Psychiatry 1997; 170: 205-28.

13 Saha S, Chant D, McGrath J. A systematic review of mortality in schizophrenia - is the differential mortality gap worsening over time? Arch Gen Psychiatry 2007; 64: 1123-32.

14 Mortensen PB, Juel K. Mortality and causes of death in first admitted schizophrenic patients. Br J Psychiatry 1993; 163: 183-9.

15 De Hert M, Peuskens J. Psychiatric aspects of suicidal behavior: schizophrenia. In International Handbook of Suicide and Attempted Suicide (eds K Hawton, K van Heeringen): 121-34. John Wiley and Sons, 2000.

16 Phillips MR, Yang GH, Li SR, Li Y. Suicide and the unique prevalence pattern of schizophrenia in mainland China: a retrospective observational study. Lancet 2004; 364: 1062-8.

17 Ran MS, Chen EYH. Suicide and schizophrenia in China. Lancet 2004; 364 1016-7. 
18 Xiang M, Ran M, Li S. A controlled evaluation of psychoeducation family intervention in a rural Chinese community. Br J Psychiatry 1994; 165: 544-8.

19 Tirupati SN, Padmavati R, Thara R, Mccreadie RG. Psychopathology in nevertreated schizophrenia. Compr Psychiatry 2006; 47: 1-6.

20 Ran MS, Xiang MZ, Li SX, Shan YH, Huang MS, Li SG, et al. Prevalence and outcome of schizophrenia in a Chinese rural area: an epidemiological study. Aust N Z J Psychiatry 2003; 37: 452-7.

21 World Health Organization. The ICD-10 Classification of Mental and Behavioral Disorders: Clinical Descriptions and Diagnostic Guidelines. WHO, 1992.

22 Wing JK, Cooper JE, Sartorius N. The Measurement and Classification of Psychiatric Symptoms. Cambridge University Press, 1974.

23 Liu JQ, Wang CH. Social Disability Screening Schedule (SDSS). In Handbook of Mental IIIness Epidemiological Investigation (eds YC Shen, CH Wang): 60-7. People Health Press, 1985.

24 Storosum JG, van Zwieten BJ, Wohlfarth T, de Haan L, Khan A, van den Brink W. Suicide risk in placebo vs active treatment in placebo-controlled trials for schizophrenia. Arch Gen Psychiatry 2003; 60: 365-8.

25 Rathbone J, Zhang L, Zhang MM, Xia J, Liu X, Yang Y, et al. Chinese herbal medicine for schizophrenia. Cochrane systematic review of randomised trials. Br J Psychiatry 2007; 190: 379-84.

26 Montout C, Casadebaig F, Lagnaoui R, Verdoux H, Philippe A, Begaud B, et al. Neuroleptics and mortality in schizophrenia: prospective analysis of deaths in a French cohort of schizophrenic patients. Schizophr Res 2002; 57: 147-56.

27 Qin P, Nordentoft M. Suicide risk in relation to psychiatric hospitalization: evidence based on longitudinal registers. Arch Gen Psychiatry 2005; 62: 427-32.

28 Palmer BA, Pankratz VS, Bostwick JM. The lifetime risk of suicide in schizophrenia: a reexamination. Arch Gen Psychiatry 2005; 62: 247-53.
29 Jeste DV, Harris MJ, Krull AJ, Kuck J, McAdams LA, Heaton R. Clinical and neuropsychological characteristics of patients with late-onset schizophrenia. Am J Psychiatry 1995; 152: 722-30.

30 Black K, Peters L, Rui Q, Milliken $\mathrm{H}$, Whitehorn D, Kopala LC. Duration of untreated psychosis predicts treatment outcome in an early psychosis program. Schizophr Res 2001; 47: 215-22.

31 Ran MS, Xiang MZ, Conwell Y, Lamberti JS, Huang MS, Shan YH, et al. Comparison of characteristics between geriatric and younger subjects with schizophrenia in community. J Psychiatric Res 2004; 38: 417-24.

32 Gureje O, Bamidele R. Thirteen-year social outcome among Nigerian outpatients with schizophrenia. Soc Psychiatry Psychiatr Epidemiol 1999; 34: $147-51$.

33 Green Al, Canuso CM, Brenner MJ, Wojcik JD. Detection and management of comorbidity in patients with schizophrenia. Psychiatr Clin North Am 2003; 26: $115-39$.

34 Goff DC, Cather C, Evins AE, Henderson DC, Freudenreich O, Copeland PM, et al. Medical morbidity and mortality in schizophrenia: guidelines for psychiatrists. J Clin Psychiatry 2005; 66: 183-94.

35 World Health Organization. Project Atlas: Mapping Mental Health Resources Around the World. WHO, 2001.

36 Oosthuizen P, Emsley RA, Keyter N, Niehaus DJ, Koen L. Duration of untreated psychosis and outcome in first-episode psychosis. Perspective from a developing country. Acta Psychiatr Scand 2005; 111: 214-9.

37 Tirupati NS, Rangaswamy T, Raman P. Duration of untreated psychosis and treatment outcome in schizophrenia patients untreated for many years. Aust N Z J Psychiatry 2004; 38: 339-43.

38 Ran MS, Chan CLW, Chen EYH, Xiang MZ, Caine ED, Conwell Y. Homelessness among patients with schizophrenia in rural China: a 10-year cohort study. Acta Psychiatr Scand 2006; 114: 118-23. 